\title{
«No me toca el corazón»: examinando las políticas para la diáspora en Galicia y el Véneto
}

\author{
Ana Irene Rovetta Cortés \\ Universidad Nacional de Jujuy / CONICET \\ anairene.rovetta@gmail.com
}

Recepción: 06-03-2017

Aceptación: 09-09-2017

Publicación: 04-05-2018

\section{Resumen}

En un momento en que las políticas para la diáspora están en auge a nivel global y la mayor parte de las investigaciones estudia iniciativas generadas desde los Estados nación, este artículo examina las políticas para la diáspora desplegadas desde una escala más pequeña. Tomando como casos de estudio las medidas de dos regiones de España e Italia (Galicia y el Véneto), se analizan los antecedentes, las características, las motivaciones y la evolución de las políticas regionales para la diáspora y se exploran algunas de sus consecuencias. El artículo adopta la perspectiva de la antropología de las políticas para analizar las políticas para la diáspora, y explora sus consecuencias a partir de un trabajo etnográfico que incorpora las narraciones de dos generaciones de migrantes que pueden categorizarse como diáspora. Se revelan un incremento del lenguaje economicista en las políticas y un escaso interés hacia las mismas por parte de los migrantes entrevistados.

Palabras clave: políticas; diáspora; narraciones migrantes; Italia; España

\section{Abstract. "It doesn't touch my heart": Examining diaspora policies in Galicia and Veneto}

At a time when diaspora policies are on the rise globally and most research is focusing attention on initiatives developed by nation-states, this paper examines diaspora mechanisms generated on a smaller scale. Taking the diaspora policies implemented by two regions of Spain and Italy (Galicia and Veneto) as case studies, this paper analyzes the premises, characteristics, motivations, and evolution of these initiatives and explores some of their consequences. The paper employs an anthropology of policy lens to analyze diaspora policies. An ethnographic approach is used to explore some of the consequences of diaspora policies by examining the narratives of two generations of migrants who can be categorized as diaspora. An increase in the economic language of policies and little interest towards diaspora policies among migrants are revealed.

Keywords: policies; diaspora; migrant narratives; Italy; Spain 


\section{Sumario}
1. Introducción
6. Describiendo las características
2. Descubriendo el marco teórico y la evolución de las políticas vénetas para la diáspora
3. Presentando el estudio
4. Examinando los antecedentes de las políticas regionales para la diáspora
5. Describiendo las características y la evolución de las políticas gallegas para la diáspora
7. Interpretando las motivaciones tras las políticas regionales para la diáspora
8. Explorando algunas consecuencias de las políticas regionales para la diáspora
9. Consideraciones finales
Referencias bibliográficas

\section{Introducción}

En la actualidad, multitud de gobiernos de todo el globo han comenzado a desarrollar políticas específicas para aquella población que, residiendo en el extranjero, consideran propia (Agunias, 2009; Délano y Gamlen, 2014; Ragazzi, 2014).

Entre los múltiples emplazamientos en que este tipo de iniciativas han proliferado, se encuentran países del oeste y el centro de Europa, como Alemania, Bélgica y Francia, del este, como Polonia y Ucrania, y también países del sur de Europa, como España e Italia (Gamlen, 2008; Ragazzi, 2014). En estos últimos, sin embargo, las políticas para la diáspora han adquirido una envergadura particular, pues no han sido generadas únicamente a nivel estatal, sino que, debido a la gestión multinivel de las migraciones, han sido desplegadas también por gobiernos subnacionales. Es decir, en España e Italia no se han desarrollado solo medidas centralizadas para la diáspora, sino que distintos gobiernos regionales y locales han incorporado iniciativas específicas para su propia diáspora (Cavas y Sánchez, 2007; Cook-Martin y Viladrich, 2009; Fusaro, 2009; Tintori, 2009).

Debido a la singularidad de estos casos, este artículo examina las políticas para la diáspora desarrolladas desde el ámbito regional, entendiendo por tal las comunidades autónomas en España y las regiones en Italia ${ }^{1}$. Esta decisión está justificada si se tiene en cuenta que, desde que comenzaran los procesos de descentralización de competencias en las décadas de 1970 y 1980, estas unidades territoriales han ganado autoridad y capacidad administrativa en materias relevantes como la educación, la sanidad, la atención a inmigrantes y, también, los vínculos con la diáspora. Si bien esta última materia no ha tenido la misma

1. España e Italia están divididas en comunidades autónomas y regiones respectivamente. España tiene 17 comunidades autónomas e Italia tiene 20 regiones. 
popularidad en todas las regiones de España e Italia, hay numerosas regiones en las que ha adquirido una importancia notoria. Entre ellas, se encuentran la Comunidad Autónoma de Galicia y la Región del Véneto, dos regiones norteñas que presentan elementos característicos y, en cierta medida, similares en lo que respecta a las condiciones político-jurídicas que han desarrollado para su diáspora. Ya que ambas regiones han desplegado iniciativas específicas hacia su diáspora en países de América Latina y, más concretamente, hacia su diáspora en Argentina.

Precisamente por el interés que ambas comparten hacia la diáspora residente en dicho país, y porque ambas se encuentran entre las regiones hacia las que se ha dirigido la población argentina (Actis y Esteban, 2007; Rhi-Sausi y García, 1992) desde que los flujos migratorios entre los tres países se revirtieran en la segunda mitad del siglo XX (Cook-Martin, 2013), este artículo pretende analizar y comparar los mecanismos desarrollados desde cada una de estas regiones. El objetivo central es, por tanto, examinar: (a) los antecedentes de las políticas regionales para la diáspora; (b) sus características y evolución; (c) las motivaciones con las que fueron diseñadas, y (d), de forma exploratoria, algunas consecuencias de las mismas.

El interés por profundizar en el conocimiento respecto a estas iniciativas está relacionado, asimismo, con el contexto histórico y geográfico más amplio en que tienen lugar, pues, mientras la Unión Europea está buscando armonizar las políticas migratorias de sus Estados miembros con vistas a controlar y reducir la entrada de personas procedentes de África, Asia y América Latina (Feldman, 2012), los gobiernos de estas regiones están queriendo «evitar la dimensión y mediación de los gobiernos centrales» (Tintori, 2009: 51), en un afán de gestionar sus propios vínculos con aquella población que, residiendo fuera del territorio, consideran propia.

La presentación del estudio se estructura, en este artículo, en siete apartados. En el primero se descubre el marco teórico de la investigación. En el segundo se introducen las principales características del encuadre metodológico. En el tercer apartado se analizan los antecedentes de las políticas regionales para la diáspora en España e Italia. En los apartados cuarto y quinto se detallan las particularidades y el desarrollo de estas políticas a partir de un análisis descriptivo de todas las iniciativas desplegadas en las regiones de Galicia y el Véneto. En el sexto se propone un análisis interpretativo respecto a las motivaciones que subyacen en las políticas para la diáspora de ambas regiones. En el séptimo apartado se exploran algunos de los efectos que dichas medidas han tenido en las migraciones de retorno de la diáspora en un escenario en el que los datos oficiales no están disponibles al público. Para ello, se incorporan las narraciones respecto a las políticas para la diáspora de personas que pueden entrar en la categoría de miembros de la diáspora que han retornado a la patria. Finalmente, se ofrecen las principales conclusiones y se discuten los resultados en relación con las evidencias más relevantes de investigaciones previas. 


\section{Descubriendo el marco teórico}

Las iniciativas gubernamentales dirigidas hacia aquella población que, residiendo en el extranjero, se considera propia - denominadas usualmente «políticas de compromiso con la diáspora» (Ancien et al., 2009) o "mecanismos para la diáspora» (Gamlen, 2008) - se han dirigido, en todos los casos, hacia quienes han abandonado el territorio (los emigrantes) y, en frecuentes ocasiones, también hacia quienes descienden de aquellos que, tiempo atrás, abandonaron el territorio: los hijos y nietos de emigrantes y, esporádicamente, también sus biznietos y tataranietos. En este artículo adopto la expresión "políticas para la diáspora» debido a que las iniciativas examinadas están dirigidas no solo a los emigrantes, sino también (y fundamentalmente) a sus descendientes.

Pese a que la distinción generacional respecto a los destinatarios de este tipo de políticas migratorias puede parecer trivial, considero que es relevante por dos motivos. En primer lugar, tal distinción muestra los contornos de cada comunidad política, desvelando quién queda incluido y quién excluido de esta en función del número de generaciones sucedidas desde el primer desplazamiento documentado. En segundo lugar, esta distinción entraña un debate conceptual respecto a las nociones de emigración y diáspora, pues estas políticas suelen apelar a la diáspora con independencia de que se orienten a los emigrantes y/o a sus descendientes. Esto revela una utilización política del concepto diáspora mucho más dúctil que aquella que impera en el ámbito científico, donde tradicionalmente se ha vinculado el término a un fenómeno de dispersión geoespacial de población que requiere de tiempo para su formación. En este sentido, cabe mencionar la definición de Roger Brubaker (2005), uno de los principales exponentes en estudios sobre la diáspora, quien propone tres características mínimas que la diáspora debe cumplir para ser considerada como tal: dispersión en el espacio, orientación hacia la patria de origen y mantenimiento de fronteras a lo largo del tiempo a través de las generaciones.

El proceso de difuminación conceptual en el ámbito político ha llevado a autores como Alexandra Délano y Alan Gamlen a plantear que, «más que buscar consenso en las definiciones, las investigaciones futuras deberían examinar cómo y por qué el término [diáspora] es empleado por actores políticos y con qué efectos» (Délano y Gamlen, 2014: 179). Si bien esta invitación a realizar estudios enraizados es pertinente, estimo, no obstante, que es fundamental no perder de vista que la falta de diferenciación de las nociones de emigración y diáspora no solo populariza una terminología más laxa respecto a esta última, sino que puede incidir en el modo en que concebimos los límites espaciotemporales de cada comunidad política.

La extensión planetaria de las políticas para la diáspora ha sido explicada a partir de dos factores: uno económico y otro cultural. Según autoras como Dovelyn R. Agunias y Kathleen Newland (2012), los gobiernos que han implementado este tipo de políticas han interpretado que existe un nexo entre desarrollo y diáspora que ha llevado a concebir a los integrantes de la diáspora como potenciales emisores de remesas y/o como inversores. Según 
autores como Christian Joppke (2005) o Zlatko Skrbis (1999), los promotores de estas iniciativas gubernamentales han considerado, principalmente, que los miembros de la diáspora son portadores de los mismos valores y costumbres de aquella población que reside en el territorio y, por tanto, son merecedores de reconocimiento y actuaciones específicas.

En lo que respecta al tipo de políticas que han desarrollado los distintos gobiernos nacionales, varios investigadores han ofrecido estudios comparativos (Gamlen, 2008; Margheritis, 2015; Ragazzi, 2014; Skrentny et al., 2009).

Alan Gamlen (2008), quien considera que las relaciones entre Estados y diásporas no deberían ser cuestionadas o vistas como «anormales», ha estudiado las políticas de 64 Estados, entre los que se encuentra Italia. A partir de dicho análisis, el autor propone una distinción entre los «mecanismos para la construcción de la diáspora», que incluyen programas para reconocer y cultivar los vínculos con la diáspora, y los «mecanismos de integración de la diáspora», centrados en garantizar derechos y extraer obligaciones. Según Gamlen, cada uno de los Estados analizados ha desarrollado los mecanismos en diverso modo: a veces simultáneamente y a veces de forma alternativa. En el caso de Italia, el autor identifica la implementación de ambos mecanismos, pues el Estado permite la doble nacionalidad, el derecho a voto a sus connacionales residiendo en el extranjero y cuenta, además, con unidades administrativas desde las que gestionar los vínculos con la diáspora. Lo cual puede extrapolarse, también, al caso de España.

Francesco Ragazzi, quien ha analizado las iniciativas desplegadas por 35 Estados, entre los que se encuentran Italia y España, formula una tipología de cinco perfiles en función del grado de interés que cada Estado ha manifestado hacia su diáspora. Los Estados «nación global» serían aquellos en los que se ha desplegado la mayor cantidad de políticas posibles hacia la diáspora; los Estados «expatriados», aquellos centrados en políticas culturales y educativas; los Estados de "trabajo controlado», aquellos en que se prevén planes de inversión para el retorno de la diáspora; los Estados «cerrados», aquellos que restringen la movilidad internacional, y los Estados «indiferentes», aquellos en los que no hay interés alguno en mantener vínculos con la diáspora. Este autor, que identifica, además, «un giro desde el liberalismo de bienestar hacia el neoliberalismo» (Ragazzi, 2014: 82), ubica a España e Italia en el grupo de los Estados expatriados.

Por su parte, Ana Margheritis, quien ha examinado las políticas desplegadas desde cinco Estados latinoamericanos en los que la emigración ha sido significativa en las últimas décadas (Argentina, Uruguay, Brasil, Ecuador y México), concluye que, pese al carácter incipiente e intermitente de muchas de las iniciativas propuestas, el objetivo de estos países ha sido el «cortejo» de su diáspora para conseguir «el apoyo y los recursos de sus ciudadanos residiendo en el extranjero" (Margheritis, 2015: 13).

Finalmente, John Skrentny, Stephanie Chan, Jon E. Fox y Denis Kim (2009), quienes optan por una comparación entre las iniciativas desplegadas en Estados de dos continentes, identifican importantes diferencias entre las 
políticas europeas y asiáticas. Según estos autores, mientras los países europeos asumen un rol protector por el cual es responsabilidad estatal favorecer los vínculos y el eventual retorno de la diáspora; los países asiáticos optan por una lógica económica neoliberal por la cual son los miembros de la diáspora quienes deben demostrar merecer el reconocimiento y el ocasional regreso a la patria.

\section{Presentando el estudio}

El presente artículo se basa en una investigación llevada a cabo entre los años 2012 y 2015 en las regiones de Galicia y el Véneto. En ellas se condujo una investigación cualitativa desde la perspectiva de la teoría enraizada en su versión constructivista (Charmaz, 2006) que incluyó el estudio, por un lado, de las políticas para la diáspora desplegadas por los gobiernos de estas regiones, y por otro, de las narraciones de miembros de familias migrantes procedentes de un país, Argentina, en el que reside población que puede ser considerada como diáspora española o italiana.

Como se anticipó en la introducción, el objetivo del presente artículo es conocer: (a) los antecedentes de las políticas para la diáspora de estas regiones; (b) sus características y evolución; (c) las motivaciones con que fueron diseñadas, y (d), de forma exploratoria, algunas de sus consecuencias, particularmente aquellas relativas al retorno. Esto último se realiza debido a que ambas regiones han dirigido programas específicos hacia la que proyectan como su población residente en Argentina en un momento histórico en que se han producido desplazamiento desde Argentina hacia estas regiones.

Estas regiones comparten, además de su interés por la diáspora en Argentina, algunas características que las asemejan: (a) poseen una fuerte noción de comunidad, respaldada por una historia y un lenguaje ${ }^{2}$ propios; (b) han experimentado ciclos económicos similares en los últimos dos siglos ${ }^{3}$; (c) han sido gobernadas con frecuencia por partidos conservadores ${ }^{4}$ en las últimas décadas del siglo XX, y (d) se han convertido en lugares de destino de población extran-

2. El gallego es reconocido como idioma en España y tiene carácter de cooficialidad junto al castellano en la Comunidad de Galicia a partir del Estatuto de Autonomía de Galicia de 1981 (Ley Orgánica 1/1981). El véneto fue reconocido como lengua en 2007 por el Consejo Regional del Véneto (Ley Regional 8/2007), pero mantiene un estatus dialectal a nivel nacional.

3. Sufrieron crisis económicas a finales del siglo XIX y comienzos del siglo XX, cuando sus economías estaban centradas en la agricultura. Durante la segunda mitad del siglo XX, cuando orientaron sus economía hacia la industria y el sector terciario, comenzaron un crecimiento económico sostenido, que se vio interrumpido en 2008 con la irrupción de la crisis financiera internacional.

4. Los partidos de derechas han gobernado la Región del Véneto desde 1995. Primero con Forza Italia e Il Popolo della Libertà y, desde 2010, con la Lega Veneta. En la Comunidad Autónoma de Galicia, el Partido Socialista estuvo en el poder únicamente entre 1987-1990 y 2005-2009. El Partido Popular gobernó en los períodos 1982-1987, 1990-2005 y desde 2009 hasta la actualidad. 
jera, entre la que se encuentran personas procedentes de Argentina ${ }^{5}$. Entre las diferencias, cabe señalar la distinta dimensión y densidad poblacional de cada una: Galicia posee cuatro provincias y una población inferior a tres millones de personas; frente a las siete provincias del Véneto, en las que reside una población levemente inferior a cinco millones de personas.

A fin de indagar sobre los antecedentes de las políticas para la diáspora, se realizó una búsqueda bibliográfica respecto a la historia migratoria de estas regiones, examinando particularmente las partidas de los respectivos territorios durante los últimos dos siglos.

Para conocer las características, la evolución y las motivaciones con que fueron diseñadas las políticas para la diáspora, se recurrió a la herramienta teóricometodológica de la antropología de las políticas (Shore y Wright, 1997; Gil Araujo, 2010). Desde ese encuadre, se examinaron todas las leyes, los planes, proyectos, $\mathrm{y}$ programas identificados a través de una búsqueda bibliográfica (offline y online) y de una serie de entrevistas con expertos (responsables políticos y trabajadores de la Administración).

Finalmente, para responder de forma exploratoria a algunas de las consecuencias de dichas políticas en un escenario en el que los datos oficiales no están disponibles al público, algo frecuente en las políticas para la diáspora (Agunias, 2009), se llevó a cabo un trabajo de campo etnográfico que incluyó entrevistas a 52 personas pertenecientes a una veintena de familias de clase media que cuentan con antepasados migrantes de España e Italia, y que se han desplazado de uno de los países en los que se han implementado todas las políticas para la diáspora gallega y véneta: Argentina. Se optó por esta estrategia para conocer el rol que han jugado en los desplazamientos de esta población las políticas para la diáspora, prestando particular atención hacia aquellas iniciativas generadas para promover el retorno. Quedaron fuera del foco de este estudio, por tanto, las consecuencias de otras políticas regionales (leyes, programas y planes) dirigidas a aquellos miembros de la diáspora que no han regresado a la región.

En lo relativo a las entrevistas, cabe señalar que, tanto las realizadas con expertos como aquellas conducidas con miembros de familias migrantes, se realizaron durante los meses de febrero y diciembre de 2013. Primero en la Región del Véneto, desde febrero hasta agosto, y posteriormente en Galicia, desde septiembre hasta fin de dicho año.

El contacto con los expertos en el Véneto incluyó varios encuentros con: (a) un jefe de sección de la Ventanilla Única para la Inmigración en la ciudad de Padua, la cual depende de la Prefectura para la Inmigración de la Región,

5. La migración entre Argentina, España e Italia se invierte en la década de 1960, y aumenta de forma significativa en momentos de inestabilidad política y económica en Argentina: durante la dictadura de Videla (1976-1983), la crisis de hiperinflación (1989) y la crisis del corralito (2001). Pese a que es difícil medir la presencia de ciudadanos argentinos en los países euromediterráneos como resultado de los acuerdos de doble nacionalidad (en vigor desde 1971), los estudios de Walter Actis y Fernando Esteban (2007) y de José Luis RhiSausi y Miguel Ángel García (1992) revelan una presencia significativa de esta población en Galicia y el Véneto. 
y (b) el secretario de una asociación de emigrantes, Vénetos en el Mundo (en italiano Veneti nel Mondo), que promovió, en colaboración con el gobierno regional, varias iniciativas para la diáspora. En Galicia, la interacción con expertos incluyó a: (a) un trabajador del Área de Inmigración, la cual forma parte de la Consejería de Trabajo y Bienestar de la Xunta de Galicia, y (b) una responsable del Área de Retorno, dependiente de la Secretaría General de Emigración, ambas ubicadas en la ciudad de Santiago de Compostela.

El contacto con las familias, por otro lado, se estableció a partir de la observación participante en dos asociaciones culturales argentinas y de la técnica de bola de nieve, con contactos facilitados tanto por personas cercanas a la investigadora como por los propios entrevistados. La opción por las distintas vías de acceso se hizo con intención de ampliar la variedad de casos y maximizar las diferencias en las características de los participantes (para más detalle, ver las tablas del anexo 1, sobre el perfil de los entrevistados).

Durante el trabajo de campo, se procedió a transcribir tanto las entrevistas como las notas etnográficas, y se comenzó el análisis de dicho material siguiendo varias fases de codificación. Durante la primera fase, se utilizó el programa informático Atlas.ti siguiendo los métodos de codificación elementales y afectivos propuestos por Johnny Saldaña (2009). En la segunda fase se reorganizaron y revisaron los datos ya codificados con la finalidad de encontrar las relaciones entre las diferentes temáticas tratadas e identificar la relevancia de cada una de ellas.

A continuación se presentan los antecedentes de las políticas regionales para la diáspora en España e Italia, para pasar con posterioridad a describir e interpretar las políticas desplegadas desde la Comunidad Autónoma de Galicia y la Región del Véneto.

\section{Examinando los antecedentes de las políticas regionales para la diáspora}

La emigración durante el período de migración de masas de Europa hacia América (1880-1914) fue particularmente acusada en algunas regiones de España e Italia, entre las que se encuentran Galicia y el Véneto. Galicia ocupa el primer lugar en el ranking de regiones emisoras españolas; entre 1857 y 1930 vio partir a más de 1.000.000 de personas (Farías, 2008). El Véneto, por su parte, es la región septentrional italiana con mayor número de emigrantes ${ }^{6}$; entre 1876 y 1978, cerca de 720.000 personas abandonaron la región para dirigirse al continente americano (Nascimbene, 1994).

El hecho de que el fenómeno migratorio afectara más a unas regiones que a otras ha sido rememorado por los gobiernos de las regiones más afectadas por estos flujos migratorios y ha conducido a que se generen, en las últimas cuatro décadas, políticas destinadas a fortalecer los vínculos con quienes son considerados como su diáspora, es decir, aquellos compatriotas que emigraron $\mathrm{y}$ sus descendientes.

6. Solo la superan en número cuatro regiones meridionales: Sicilia, Campania, Calabria y Abruzos (Nascimbene, 1994). 
En España, cinco comunidades autónomas han desarrollado políticas para su diáspora: Galicia, Andalucía, Asturias, Canarias y Extremadura (Cavas y Sánchez, 2007). En Italia, 11 regiones han hecho lo mismo: primero, en el norte del país, Véneto, Lombardía, Liguria y Piamonte (Fusaro, 2009), y después en el sur, en Basilicata, Campania, Calabria, Molise, Apulia, Cerdeña y Sicilia (Tintori, 2009).

Los gobiernos de estas regiones han interpretado la migración transatlántica de finales del siglo XIX y comienzos del siglo XX como un fenómeno eminentemente regional y no estatal. Han considerado que la emigración fue una consecuencia de los problemas económicos que asolaban las regiones, vinculándola, por tanto, a una serie de crisis en los sistemas de producción agrícola que causó desempleo, miseria y hambre. Esta lectura - que excluye por completo cualquier atisbo de conflicto político entre las causas de la migración transoceánica - ha llevado a que los recuerdos asociados a estos desplazamientos sean enaltecidos. De modo que los emigrantes de estos territorios no son rememorados solo como personas que partieron a buscar una vida mejor en el otro lado del océano, sino que, a través de lecturas nostálgicas y plagadas de romanticismo, son considerados como héroes o mártires, personas nobles y trabajadoras que se vieron obligadas a abandonar sus tierras a pesar de su (siempre incuestionable) amor por la patria. Por consiguiente, los distintos gobiernos de estas regiones han interpretado que: (a) las asociaciones que los migrantes crearon en los países de destino tuvieron el objetivo primordial de mantener intacta «la» pertenencia a la comunidad regional, y que (b) los emigrantes transmitieron (pacíficamente) los valores y costumbres regionales a sus descendientes.

A partir de estas lecturas, los gobiernos regionales contemporáneos consideran que, en los países de destino, sigue viviendo en la actualidad —más de 100 años después de que terminara el período de migración de masas europeopoblación procedente de la región de origen. Por este motivo, han generado, desde las últimas décadas del siglo XX, una serie de medidas para mantener $\mathrm{y}$ reforzar los vínculos con la diáspora.

Teniendo en cuenta que cada región ha desplegado sus propias estrategias, a continuación se describen las políticas para la diáspora desarrolladas desde cada una de ellas para ofrecer, con posterioridad, una comparación e interpretación de las motivaciones subyacentes a estas iniciativas y examinar, de forma exploratoria, algunas de las consecuencias asociadas a ellas, principalmente aquellas relativas a los programas de retorno, a través de las narraciones de migrantes procedentes de Argentina que cuentan con antepasados españoles e italianos y pueden, por tanto, entrar en la categoría de diáspora.

\section{Describiendo las características y la evolución de las políticas gallegas para la diáspora}

Desde la aprobación del Estatuto de Autonomía de Galicia en 1981, los distintos gobiernos de la comunidad autónoma, tanto del Partido Popular como del Partido Socialista, han desarrollado programas para conservar los lazos con la población gallega que emigró, así como con sus descendientes. 
En 1983 se aprobó la Ley de Reconocimiento de la Galleguidad (Ley 4/1983), cuyo objetivo era reforzar los vínculos con las «comunidades gallegas residentes en el extranjero». Para ello, la ley proponía: (a) el reconocimiento de «galleguidad» a las entidades asociativas sin ánimo de lucro que, asentadas fuera del territorio nacional, tuvieran como objetivo la conservación de lazos culturales y sociales con Galicia, y (b) la inserción de dichas entidades en la vida social y cultural gallega, sin que ello comportase la concesión de derechos políticos. No obstante, dos años después, se instauró, tanto a nivel estatal (Ley 5/1985) como autonómico (Ley 8/1985), el derecho a voto de los compatriotas residiendo en el exterior.

En la década de 1990 se fomentaron, además, intercambios socioculturales con las asociaciones de emigrantes en el extranjero y viajes de tipo turístico para emigrantes y descendientes de segunda y tercera generación.

En 2001, el objetivo del gobierno regional pasó a ser no solo mantener relación con las comunidades gallegas en el exterior, sino también gestionar el retorno de sus miembros. De hecho, en 2002 comenzó la concesión de ayudas extraordinarias a emigrantes gallegos retornados, las cuales se han renovado anualmente desde entonces. Estas prestaciones se generaron para ayudar a cubrir los gastos extraordinarios derivados del viaje para aquellos miembros de la diáspora que optan por el retorno, así como para sus familiares (cónyuge, hijos, hijas, nietos y nietas), siempre que se encuentren en situación de necesidad y puedan demostrarlo. Se trata de una medida que no ha establecido diferencia respecto a los países de los cuales procede la diáspora, pero que ha generado una distinción entre la población que llega a la comunidad autónoma en función de su origen personal o familiar. Desde que se implantaron estas ayudas, tener un antepasado gallego (padre, madre, abuelo o abuela) supone poder optar a conseguir mayores facilidades que en el caso de la población extranjera que cuenta con cualquier otro origen familiar.

Por otra parte, en este período se desplegaron, además, otras intervenciones específicas hacia la diáspora en América Latina. En abril del año 2002, se creó un organismo denominado Fundación Galicia Emigración, que se mantuvo en funcionamiento hasta 2010. El objetivo de dicha fundación era, inicialmente, enviar ayuda económica a los "gallegos y sus descendientes residentes en América Latina», particularmente a aquellos que vivían en Argentina, Brasil, Uruguay y Venezuela. La justificación ofrecida ante tal iniciativa fue que la crisis financiera argentina de 2001 se expandió a otros Estados cercanos debido a la interdependencia de las economías del continente, lo que ponía en situación de riesgo a población vulnerable (la tercera edad y la infancia). Así pues, entre 2002 y 2005 , estuvieron en funcionamiento las ayudas para la prestación de servicios de carácter sociosanitario a favor de los emigrantes gallegos y sus descendientes en estos países.

Dichas ayudas se gestionaban a través de los centros gallegos y otras instituciones que realizaran labores de protección de la infancia y prestaciones sociosanitarias con personas en situación de necesidad y en las cuales una parte importante de los beneficiarios fueran de origen gallego. En otras palabras, la 
iniciativa se planteó en términos de solidaridad, pero se basaba (nuevamente) en una distinción entre los beneficiarios de las ayudas en función de su origen personal o familiar.

Durante el gobierno socialista (2005-2009) se buscó fortalecer aún más los lazos con las comunidades gallegas residentes en el exterior y favorecer conjuntamente la inserción en el territorio de «inmigrantes» (es decir, personas de otros países sin antepasados gallegos) y «retornados» (miembros de la diáspora gallega) a través de ayudas y subvenciones a organismos locales (ayuntamientos, asociaciones y entidades sin ánimo de lucro). Se delegó en ellos la labor de acogida, información, orientación, atención e integración de los colectivos de inmigrantes y retornados, generando una estrategia de gestión multinivel desde el ámbito autonómico hacia el gobierno local, en la que se identifican, además, procesos de externalización de algunas intervenciones desde el ámbito público hacia organizaciones no gubernamentales. En 2009, coincidiendo con la vuelta al poder del Partido Popular y el inicio de la actual crisis económica, se desmantelaron estas iniciativas.

En enero de 2013 se produce, sin embargo, un nuevo cambio. El organismo regional que se ocupaba de atender a los recién llegados a la región (inmigrantes y retornados) pasa a ocuparse en exclusiva de las comunidades gallegas en el exterior y de las políticas de emigración y retorno a Galicia. Los colectivos inmigrantes (siempre extracomunitarios) comienzan a ser atendidos desde otra consejería. Todos los programas que hasta ese momento atendían de forma conjunta a la población que llegaba al territorio, con independencia de su origen (o el origen de sus antepasados), se escinden.

Después de este cambio, se mantienen en vigor los programas que facilitan los viajes de turismo de miembros de la diáspora (mayores y jóvenes) a Galicia y las ayudas extraordinarias a emigrantes gallegos retornados y se desarrolla una nueva medida cuyo objetivo es la promoción del autoempleo entre quienes forman parte de la categoría de retornados. Se trata de un programa que otorga subvenciones a la diáspora que retorna, y le permite sufragar los gastos (de hasta 5.000 euros) de establecimiento inicial de una actividad laboral autónoma.

Esta iniciativa añade un carácter económico-empresarial, inédito hasta entonces, a las políticas regionales. Si hasta ese momento se empleaba un lenguaje centrado en elementos culturales e históricos, en 2013 se adopta un lenguaje diferente, de corte economicista. Esta novedosa retórica se plasma en la nueva Ley de Galleguidad (Ley 7/2013), que sustituye a la anterior ley de 1983. Prueba de este giro es que dicha norma no limita sus medidas a la conservación de la cultura, la historia y el idioma gallego, sino que incluye (a diferencia de la anterior) objetivos económicos.

Dicha norma introduce otro cambio y es que restablece los requisitos para el reconocimiento de los miembros de la diáspora. Se resuelve que son miembros de la diáspora las personas gallegas y nacidas en Galicia, su cónyuge o persona con unión análoga a la conyugal y sus hijos, excluyendo por primera vez de cualquier iniciativa regional a los nietos de emigrantes. Pese a que no se explicita el motivo del cambio respecto a la reducción del alcance generacional 
(de tres a dos generaciones), es posible suponer que este se relacione con un deseo de limitar la cantidad de población que puede acceder a los programas vigentes para el retorno y el emprendimiento en un momento de recesión económica.

\section{Describiendo las características y la evolución de las políticas vénetas para la diáspora}

En el año 1995 el gobierno regional lanzó la primera ley para la diáspora véneta, la Ley de Intervenciones para los Vénetos en el Mundo (Ley 25/1995). Esta norma reconocía como miembros de la región a los emigrantes vénetos, así como a sus familiares y descendientes hasta la tercera generación.

Durante la segunda mitad de la década de 1990 y bajo el amparo de dicha ley, los objetivos fueron: (a) conservar y tutelar el valor de «la» identidad véneta; (b) valorizar la profesionalidad a través de procesos formativos; (c) favorecer la participación, la solidaridad y la tutela de los trabajadores de origen véneto y sus familias, y (d) facilitar la repatriación de los vénetos y sus familias.

En 2001, coincidiendo con la crisis económica argentina, surge el Plan Retorno: un plan coordinado desde el gobierno por la Asesoría para la Seguridad y los Flujos Migratorios y Véneto Trabajo (en italiano Veneto Lavoro), y por la asociación Vénetos en el Mundo (Veneti nel Mondo). El plan inicial contaba con dos proyectos: Proyecto Retorno (Progetto Rientro) y Proyecto de Retorno de Emigrantes (Progetto Rientro Emigrati), que en 2003 se fusionan en uno. El primero, descrito como experimento piloto, tenía la finalidad de promover el retorno y la inserción laboral de «italianos emigrados» residentes en Argentina, particularmente de aquellos con origen véneto hasta la tercera generación. El segundo, el Proyecto de Retorno de Emigrantes, contaba con una oficina de información para el retorno de emigrantes, cuya pretensión era unir demanda de trabajo local con oferta de trabajo sudamericana. En este caso no se incluía solo a diáspora en Argentina, sino también a la de Chile, Brasil y Uruguay.

Dentro del marco del primer proyecto, Proyecto Retorno, en 2002 se firmó una convención entre la región y Veneto Lavoro, por la cual se acordó con la empresa de electrodomésticos Electrolux-Zanussi la búsqueda de candidatos para más de 200 puestos de trabajo. Los procesos de selección y formación se realizaban en la ciudad argentina de Córdoba, y una vez finalizado el curso, se financiaba el viaje en avión, se daba trabajo y un alojamiento temporal a los retornados durante los primeros meses de estadía (de tres a seis).

Por su parte, el Proyecto de Retorno de Emigrantes gestionaba el contacto con asociaciones de emigrantes en los países latinoamericanos a través de la oficina de información, para encontrar candidatos en función de sus currículums y las ofertas laborales disponibles. En otras palabras, se trataba de un proceso individualizado de selección de potenciales migrantes en función de su origen personal y familiar, de su formación y de su experiencia laboral.

Un elemento que merece especial atención en los procesos de selección de estos programas es la cuestión del género. Según los datos publicados en 2005, 
Figura 1. Cartel de la campaña SOS Argentina en la Región del Véneto.

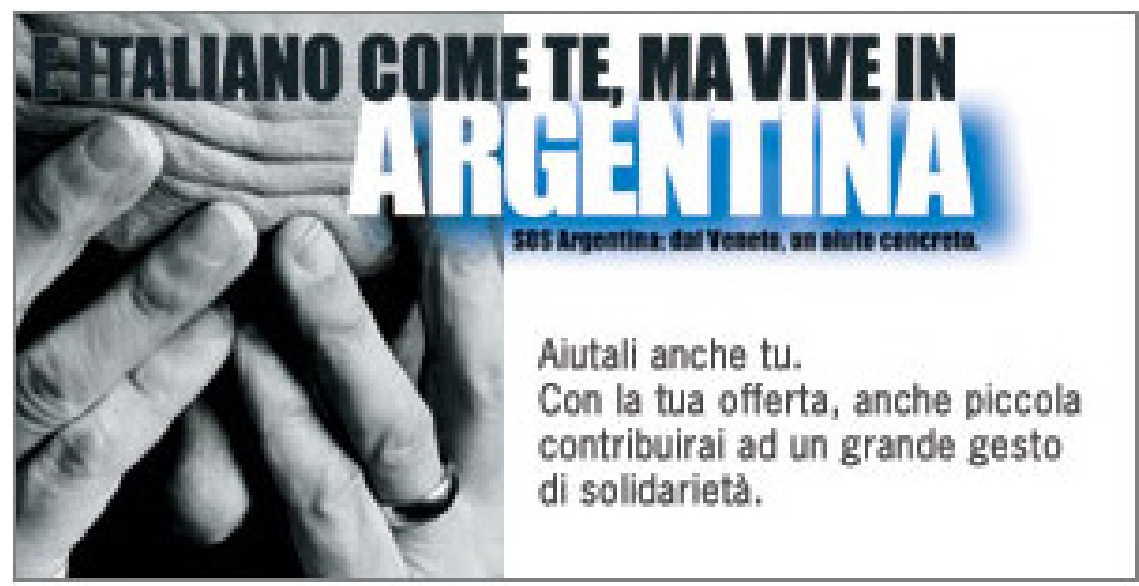

Fuente: Vénetos en el Mundo, 2002.

se constata que la participación en el Proyecto Retorno es mayoritariamente masculina (entre el 75\% y el 100\%). Se desconoce si esta desproporción de género se debe al número de solicitudes presentadas por los empresarios o por los participantes, pero teniendo en cuenta la igualdad en el acceso al derecho a la educación en Argentina y Chile es sorprendente la disparidad, no solo porque el siglo XXI está caracterizado — entre otras cosas - por la creciente movilidad internacional femenina; sino porque, particularmente, la migración de ambos países está definida por una relativa paridad en lo que se refiere a los desplazamientos internacionales.

A comienzos del siglo XXI, destacan otras iniciativas como, por ejemplo, la creación de una red de solidaridad formada por voluntarios para acoger a los recién llegados, Red Bienvenidos; y la campaña SOS Argentina, gestionada por la asociación Vénetos en el Mundo, para recaudar fondos de ciudadanos italianos con el objetivo de ayudar a los vénetos que sufrían la crisis económica del corralito en Argentina. La campaña incorporaba la utilización de carteles que fueron colocados en lugares públicos de diversas ciudades para atraer la atención de la población residente (ver figura 1).

Junto a estos planes, redes y campañas, en este período aparece otra iniciativa legislativa regional, la Ley Nuevas Normas a favor de los Vénetos en el Mundo y Facilidades para su Retorno (Ley 2/2003), que sustituye a la ley anterior de 1995 y prevé medidas que faciliten el retorno de emigrantes vénetos y descendientes hasta la tercera generación a través de ayudas para costear el viaje, el asentamiento inicial y actividades formativas y culturales.

Asimismo, durante este tiempo se mantienen los viajes de turismo y las visitas culturales organizadas, tanto a nivel regional como local, por distintas asociaciones regionales y provinciales (como Padovanos en el Mundo, Vicentinos en el Mundo, Trevisanos en el Mundo...). 
En 2005 hubo cambios en el gobierno regional que afectaron la organización de los equipos asesores y se desmantelaron los programas de retorno. Es en el año 2009 cuando la asociación Vénetos en el Mundo, junto con la Asesoría a los Flujos Migratorios de la Región del Véneto, en colaboración con las federaciones y comisiones de las asociaciones vénetas en el extranjero, lanza un nuevo proyecto para la diáspora: un proyecto denominado GlobalVen.

Esta vez el proyecto se dirige a los "jóvenes vénetos en el mundo» y no propone el retorno de la diáspora, sino la creación de una red de contactos online para que los jóvenes definidos como talentos puedan generar contactos profesionales y de emprendimiento. A través del envío online del currículum, una fotografía y un escrito sobre los vínculos que cada joven véneto tiene con asociaciones vénetas en el extranjero, se establece una red que permite a cada individuo ponerse en contacto con otros jóvenes de origen véneto que tengan intereses empresariales. En este sentido, es llamativo el aumento en el empleo de un lenguaje de tipo economicista y la disminución del recurso a una lectura sentimental (predominante en el Plan Retorno) vinculada a la historia migratoria contemporánea.

En junio de 2013, la Ley Regional 2/2003 se modifica por segunda vez, ampliando el reconocimiento de la ascendencia véneta hasta la quinta generación. Son considerados como diáspora véneta los emigrantes vénetos, sus hijos, nietos, biznietos y tataranietos. Dicho cambio puede ser interpretado como parte de la estrategia de la región para aumentar y rejuvenecer sus vínculos con la diáspora en tiempos de recesión económica.

\section{Interpretando las motivaciones tras las políticas regionales para la diáspora}

Teniendo en cuenta la descripción precedente sobre la evolución de las políticas para la diáspora de las regiones de Galicia y el Véneto, es posible identificar un giro en el tipo de iniciativas que estas regiones han desplegado a lo largo de los últimos 40 años.

Siguiendo la distinción de John Skrentny, Stephanie Chan, Jon E. Fox y Denis Kim (2009) sobre políticas europeas y asiáticas, se podría afirmar que las políticas en estas regiones han pasado de un estilo «europeo» a uno más "asiático». Ya que, si en las últimas décadas del siglo XX las políticas gallegas y vénetas para la diáspora tenían un carácter de tipo protector y se centraban en el reconocimiento y mantenimiento de lazos culturales con la diáspora, a comienzos del siglo XXI han adquirido una lógica cada vez más neoliberal, promoviendo el establecimiento de vínculos laborales y empresariales. Se trata de una transformación que coincide con la apreciación de Francesco Ragazzi (2014) sobre la tendencia hacia el neoliberalismo de las políticas desplegadas por múltiples Estados de todo el globo, y con la reflexión de Ana Margheritis (2015) sobre el propósito de estas iniciativas de captar los apoyos y recursos de la diáspora.

En este giro pueden identificarse tres fases. En la primera, se genera el interés por preservar los vínculos con las asociaciones que los emigrantes crearon 
en los países de destino. En la segunda, se produce la promulgación de leyes que delimitan quienes pertenecen a la región en función de la distancia generacional que los une con los ancestros migrantes. Y, en la tercera, destaca el desarrollo de programas que favorecen el retorno y/o la generación de vínculos empresariales en función de las necesidades del mercado laboral regional.

En consecuencia, se observa una modificación en la descripción del perfil asociado a la población en la diáspora. Ya no se considera que la diáspora esté compuesta únicamente por personas nobles y trabajadoras, étnicamente similares a la población autóctona (Cook-Martin y Viladrich, 2009), sino que se le atribuyen nuevas características de corte economicista: la población en la diáspora debe ser, además, autónoma, independiente y emprendedora.

No obstante, el giro de corte neoliberal ha tenido una magnitud diferente en cada región. En la Comunidad Autónoma de Galicia se ha percibido un aumento en la lógica economicista a partir de los nuevos programas para emprendedores, sin que ello elimine por completo la lógica anterior de protección nacionalista, pues se siguen ofreciendo ayudas económicas para el retorno a aquellos miembros de la diáspora que se encuentran en situación de necesidad.

En la Región del Véneto, sin embargo, el giro economicista es más pronunciado. Durante los primeros años del siglo XXI, cuando la coyuntura económica en la región era favorable, se promovieron programas de retorno para reclutar trabajadores en Argentina, Chile, Brasil y Uruguay para las empresas locales. Durante los años posteriores, en el momento en que empezaron a sentirse los efectos de la actual crisis financiera en la Región del Véneto, la propuesta neoliberal buscó, en cambio, mantener los vínculos empresariales con la diáspora sin promover su regreso al territorio. De este modo, esta región ha mostrado una estrategia que permite interpretar a la diáspora como una suerte de «ciudadanía de reserva». Se espera que esta retorne, o no, en función de las necesidades del mercado y las de la región, que son leídas como coincidentes. La Región del Véneto ha demostrado, además de un giro economicista más pronunciado, una mayor versatilidad a la hora de proponer políticas neoliberales para la diáspora fuera de las fronteras regionales y nacionales.

El estudio de las políticas evidencia que la Comunidad Autónoma de Galicia ha mantenido los vínculos con asociaciones de emigrantes en el extranjero en el plano de los intercambios culturales, reservando las iniciativas empresariales para aquellos miembros de la diáspora que ya han regresado al territorio. La Región del Véneto, en cambio, ha buscado activa y alternativamente trabajadores y socios empresariales en el otro lado del océano. De hecho, los programas que lanzó en el período 2001-2005 involucraron no solo al gobierno regional, a asociaciones conservadoras y a empresas locales, sino que también supusieron una gestión transfronteriza, al implicar a asociaciones de emigrantes en países de América Latina y generar organismos deslocalizados —en las ciudades de Córdoba, en Argentina, y Santiago, en Chile- desde los que seleccionar a miembros de la diáspora considerados idóneos para el mercado de trabajo regional. 
En consonancia con este giro neoliberal, las iniciativas de estas regiones en América Latina — de gran relevancia para ambas — han sido también distintas. Galicia optó por enviar ayuda económica para su diáspora tras la crisis que asoló al continente a comienzos de siglo, mientras que el Véneto envió ayuda económica, al tiempo que buscaba mano de obra para el mercado regional. Es decir, si en ambos casos estas regiones proponían medidas que distinguían a la población latinoamericana en función de su procedencia personal y familiar, la segunda llevó más lejos esta estrategia, al distinguir a dicha población no solo en función de su origen, sino también de su formación y su experiencia personal y profesional.

Por otro lado, es posible identificar otra diferencia fundamental entre las regiones al examinar los derechos políticos a los que tiene acceso la diáspora, pues solo una de estas regiones permite el voto en las elecciones regionales de sus compatriotas en el exterior.

En Italia, donde el voto para italianos en el extranjero está garantizado desde el año 2001 (Ley 459/2001), las elecciones regionales no contemplan la participación de compatriotas que residan fuera del territorio, y no ha habido hasta la fecha ninguna iniciativa en la Región del Véneto para revertir tal situación. En Galicia, en cambio, donde el voto desde el extranjero está garantizado desde 1985, se ha celebrado la entrada en vigor de la reforma de la Ley Electoral española del año 2011 (Ley 2/2011). Pues esta entraña que el voto desde el exterior deba ser solicitado o "rogado", y esto ha supuesto una notable reducción en la participación electoral de la diáspora. Lo cual, en el caso gallego, ha beneficiado al gobierno del Partido Popular, menos votado por la diáspora que el Partido Socialista.

Finalmente, a modo de síntesis, se presenta una tabla en la que se despliegan las políticas para la diáspora generadas desde estas regiones a partir de la tipología propuesta por Alan Gamlen (2008). Se identifica, de este modo, una similitud entre las iniciativas regionales y aquellas estatales en lo que respecta a la amplia variedad de mecanismos implementados.

Teniendo en cuenta que (a) Argentina fue uno de los pocos países en los que se desarrollaron todas las iniciativas de estas regiones; que (b) la migración desde Argentina hacia estas regiones ha aumentado durante la segunda mitad del siglo XX y la primera década del siglo XXI, y que (c) los datos respecto a los beneficiarios de estas políticas para la diáspora no son de dominio público, a continuación se busca conocer, a través de las narraciones de personas que entran en la categoría de diáspora que ha regresado a la patria, algunas de las consecuencias que han tenido estas iniciativas, prestando particular atención a aquellas desplegadas para promover el retorno.

Se presentan las narraciones de personas que (a) proceden de Argentina, (b) se han establecido en Galicia o el Véneto en las últimas cuatro décadas (ver anexo 1), y (c) pertenecen a una veintena de familias migrantes (9 de las cuales cuentan con antepasados - padres, madres, abuelas o abuelos- vénetos o gallegos, y 11 con antepasados migrantes españoles o italianos).

A partir de un análisis sistemático se examinan el (des)conocimiento respecto a las políticas regionales para la diáspora y las actitudes y actuaciones frente 
Tabla 1. Tipología de políticas para la diáspora desarrolladas en Galicia y el Véneto a partir de la propuesta de Alan Gamlen

\begin{tabular}{|c|c|c|c|c|}
\hline \multirow[b]{2}{*}{ Mecanismos } & \multirow[b]{2}{*}{ Objetivos } & \multirow[b]{2}{*}{ Medidas } & \multicolumn{2}{|c|}{ Regiones } \\
\hline & & & Galicia & Véneto \\
\hline \multirow{5}{*}{$\begin{array}{l}\text { Mecanismos para } \\
\text { la construcción } \\
\text { de la diáspora }\end{array}$} & \multirow{3}{*}{$\begin{array}{l}\text { Cultivo de } \\
\text { la diáspora }\end{array}$} & Proclamación de similitud étnica & $\checkmark$ & $\checkmark$ \\
\hline & & $\begin{array}{l}\text { Mantenimiento de vínculos e } \\
\text { intercambios culturales }\end{array}$ & $\checkmark$ & $\checkmark$ \\
\hline & & Financiación de viajes turísticos & $\checkmark$ & $\checkmark$ \\
\hline & \multirow[t]{2}{*}{$\begin{array}{l}\text { Reconocimiento } \\
\text { de la diáspora }\end{array}$} & $\begin{array}{l}\text { Establecimiento de legislación con } \\
\text { delimitación generacional }\end{array}$ & $\checkmark$ & $\checkmark$ \\
\hline & & $\begin{array}{l}\text { Desarrollo de organismos e iniciativas } \\
\text { específicas }\end{array}$ & $\checkmark$ & $\checkmark$ \\
\hline \multirow{6}{*}{$\begin{array}{l}\text { Mecanismos para } \\
\text { la integración } \\
\text { de la diáspora }\end{array}$} & \multirow{3}{*}{$\begin{array}{l}\text { Extensión } \\
\text { de derechos }\end{array}$} & Derecho a voto desde el exterior & $\checkmark$ & $x$ \\
\hline & & Provisión de servicios sociosanitarios & $\checkmark$ & $\checkmark$ \\
\hline & & Asistencia económica para el retorno & $\checkmark$ & $\checkmark$ \\
\hline & \multirow[t]{3}{*}{$\begin{array}{l}\text { Extracción } \\
\text { de obligaciones }\end{array}$} & $\begin{array}{l}\text { Establecimiento de programas para } \\
\text { reclutar a trabajadores }\end{array}$ & $x$ & $\checkmark$ \\
\hline & & $\begin{array}{l}\text { Desarrollo de programas de } \\
\text { emprendimiento para retornados }\end{array}$ & $\checkmark$ & $x$ \\
\hline & & Fomento de vínculos empresariales & $\checkmark$ & $\checkmark$ \\
\hline
\end{tabular}

Fuente: elaboración propia, 2017

a las distintas iniciativas. Se tienen en cuenta varios posicionamientos sociales (como edad, generación y género) en el momento de identificar y clasificar las distintas respuestas ofrecidas.

A continuación se ofrecen los principales resultados, recurriendo, para ello, a un estilo narrativo cualitativo que incorpora la reproducción de algunos fragmentos significativos de las entrevistas a fin de ilustrar las interpretaciones socioantropológicas que emergen durante el proceso de análisis inductivo.

\section{Explorando algunas consecuencias de las políticas regionales para la diáspora}

Considerando que se entrevistó a distintos miembros de 20 familias —abuelas, padres, madres, hijos e hijas adultos y menores de edad-, es necesario resaltar que, en este apartado, se analizan únicamente las narraciones de los padres y madres (25) y las de los hijos e hijas adultos (13). Las narraciones de las abuelas y los hijos e hijas menores de edad no se incluyen porque ninguno de estos integrantes de las familias migrantes contactadas disponía de información sobre las políticas para la diáspora.

Clarificada la distinción generacional que delimita las narraciones de los participantes escogidos para el presente análisis, cabe señalar que la mayor parte de los migrantes entrevistados tienden a definir su propio desplazamiento en términos de nueva migración y no como un retorno a la patria de sus ancestros. 
Si bien para la mayoría es significativo a nivel emocional residir en la región o país del que emigraron sus antepasados, su proyecto migratorio obedece a causas vinculadas, en mayor medida, con elementos económico-laborales.

En lo que respecta a las políticas regionales para la diáspora, es remarcable la falta de conocimiento que la mayor parte de los entrevistados manifiesta respecto a ellas. Con independencia de los momentos de llegada, hecho que podría haber supuesto diferencias entre quienes se desplazaron en los años en que se favoreció el retorno con programas específicos y quienes lo hicieron en otro período, hay una carencia de interés generalizada respecto a estas medidas.

En cualquier caso, cabe señalar que aunque el conocimiento de padres, madres, hijos e hijas adultos respecto a estas políticas fuera limitado, sí presenta algunas características distintivas en función de la generación migratoria. No solo ha podido observarse un nivel mayor de desconocimiento entre los hijos e hijas mayores de edad frente a sus progenitores, sino que, además, el desinterés es más alto y obedece a causas distintas.

En general, los hijos e hijas tienden a explicar su falta de interés en estas iniciativas apuntando a que su migración no fue planeada por ellos mismos, sino que la organizaron sus padres durante su minoría de edad. Sin embargo, su edad en el momento de la migración no es la única causa de su indiferencia. Otro motivo es que la mayor parte de estos jóvenes no siente que su experiencia migratoria esté directamente vinculada con la de sus antepasados migrantes. Por ello, al mencionar este tipo de medidas, suelen expresar que estas no les conciernen.

Julia ${ }^{7}$, por ejemplo, declara:

Sé que hay muchas facilidades. (...) Pero no sé en qué consisten porque, de hecho, a mí no me han servido. (...) No estoy muy involucrada en estas cosas, en el sentido de que soy argentina de familia, pero vivo en Italia, así que para mí soy italiana. No sé. Esta cosa de «italiano como tú, pero vive en Argentina», ¡para mí es argentino! No me toca el corazón, eso seguro. A lo mejor después hay alguien que lo siente, ¿̨no? Pero yo no puedo decir que lo vivo en mi piel, no me involucra en absoluto. (Julia, 26 años, estudiante universitaria, Padua, Véneto, abril de 2013)

Para Julia, como para muchos de los hijos e hijas adultos entrevistados, el desconocimiento de estas políticas está vinculado a una distancia identificatoria y emotiva. Julia recuerda haber visto la campaña SOS Argentina sobre la vía del tren en la ciudad de Padua, pero no recuerda haber vinculado la campaña a su propia vivencia de ser ella hija de argentinos a su vez descendientes de emigrantes italianos. Su interpretación respecto a las iniciativas para la diáspora es clara: los argentinos que descienden de italianos son argentinos, y ella,

7. Pseudónimos elegidos por los propios entrevistados.

8. La entrevistada lee el texto del cartel de la campaña SOS Argentina. Las entrevistas en la Región del Véneto incorporaban la imagen siguiendo la técnica de foto-elucidación. 
por su propia experiencia vital, es italiana. En el extracto, su distanciamiento afectivo queda ilustrado con dos referencias corpóreas, pues Julia afirma que no se siente apelada ni en su piel ni en su corazón.

Si bien no todos los hijos e hijas adultos se identifican tan claramente con el país en que residen (Rovetta Cortés, 2016), sí comparten la actitud de distanciamiento respecto a las medidas regionales para la diáspora al no vincular la migración de sus familias con los discursos regionales sobre la diáspora.

Por su parte, las narraciones de los padres y madres reflejan que su escaso interés en las políticas para la diáspora obedece a otras razones. La primera de ellas es el rol crucial que juegan las redes migratorias en los desplazamientos transatlánticos contemporáneos. De hecho, si la Comunidad Autónoma de Galicia y la Región del Véneto son los destinos migratorios de estas familias es debido, sustancialmente, a la existencia de redes de amigos y parientes (sobre todo, primos, primas, tíos y tías) que animan a los entrevistados a tomar la decisión migratoria, les ofrecen información sobre el lugar de destino y un primer alojamiento durante el período de asentamiento inicial.

La segunda razón es que el origen regional de los antepasados migrantes se revela como un filtro de acceso a las políticas en aquellas ocasiones en que la región de origen de los antepasados y la de residencia actual no coinciden. Dado que no todas las familias entrevistadas cuentan con antepasados de la región en la que residen, varias personas refieren haber descubierto, al buscar información respecto a este tipo de iniciativas, que no podían acceder a ellas debido al origen regional «erróneo» de sus antepasados migrantes.

Las narraciones de Rosa y Mafalda ilustran este caso:

Me acuerdo que las habíamos leído antes de venir. (...) Pero de preciso en el Véneto no, porque yo no tenía el abuelo véneto; era de la Lombardía, así que cuando me enteré de que yo no podría haber participado no busqué más. (...) Pienso que [las iniciativas para favorecer el retorno] son buenas. (Mafalda, 53 años, empleada en empresa gráfica, Padua, Véneto, julio de 2013).

Te devolvían la plata del pasaje para la gente que venía acá que era hijo de descendientes vénetos. En mi caso, yo sé que mi hermano lo quiso hacer, pero nosotros somos descendientes de molisanos, entonces no pudimos hacer eso. Tendría que haber ido a vivir a Molise un cierto período, a trabajar ahí y sé que te devolvían el valor, no sé 1000 euros, 1500 euros. El valor del pasaje. (Rosa, 31 años, trabajadora doméstica, Vicenza, Véneto, marzo de 2013)

Al conocer la imposibilidad de beneficiarse de las medidas de la Región del Véneto debido a la procedencia de sus ancestros, estas dos mujeres optaron por dejar de buscar información específica respecto a las leyes y programas regionales. Sin embargo, pese al carácter excluyente y discriminador que caracteriza a estas iniciativas, ni Rosa ni Mafalda expresan disconformidad, sino que, por el contrario, las valoran positivamente.

En relación con los programas de reclutamiento activo de la Región del Véneto en Argentina, solo una persona declaró conocer las medidas regionales 
y haberse beneficiado directamente de uno de los programas para el retorno. Se trata de Patoruzú, un padre de familia que se define a sí mismo como "prueba» del Programa Retorno:

Digamos, yo fui un poco una prueba de lo que se quería hacer, y cómo este abogado, A., como dije antes, me consiguió este trabajo, y un poco fue un test para ver cómo iba, y vieron que la gente que me había preso [contratado] a trabajar estaba contenta y yo estaba contento con el trabajo, iba todo bien; entonces se pensó en hacer lo del sportello [oficina de información], que, para mí es una cosa bárbara, fue muy bueno. Lo único que lamentablemente tuvo un problema el sportello, que no es por el sportello en sí, sino por la gente que vino. (Patoruzú, 45 años, técnico electricista, Padua, Véneto, abril de 2013)

Patoruzú conoció a un representante del gobierno de la Región del Véneto que se encontraba en la ciudad de Buenos Aires en el año 2001. Coincidieron en un encuentro de una asociación de emigrantes vénetos de la capital al que el entrevistado había acudido con su mujer. Durante la conversación con el político, este le informó sobre el programa y le animó a que participara. Tras ese encuentro, lo hizo, y fue seleccionado para trabajar como empleado en el sector técnico de una empresa de la provincia de Vicenza.

Su valoración de la experiencia durante la entrevista fue altamente positiva, mostraba agradecimiento hacia las personas concretas que lo habían ayudado: el político que trabajaba en la Asesoría para la Seguridad y los Flujos Migratorios y una persona de la asociación cultural conservadora Vénetos en el Mundo. Su criticidad iba dirigida hacia los detractores de estas iniciativas, "personas ingratas», que participaron en el programa y no vieron cumplidas sus expectativas. El hecho de que los programas incluyeran ofertas laborales exclusivamente en el ámbito empresarial privado, en el sector secundario y que, además, presentaran una escasa o prácticamente nula participación femenina no son elementos mencionados en esta o ninguna otra entrevista.

Por su parte, Teodosia, quien conocía la distribución regional en las políticas para la diáspora antes de migrar a España, narra cómo accedió a las ayudas de la Comunidad Autónoma de Extremadura, pero no para ella misma, que migró a Galicia, sino para su padre:

Cuando yo decido venirme, yo tengo un hermano solo (...). Una de las cosas que él me dijo después de deshacer el negocio, de darme la mitad, de hacer todas las cuentas, la economía, todas perfectas, él me dijo: 'Yo no me quedo con papá. (...) Entonces como él [padre] es extremeño yo me puse en contacto con la Junta de Extremadura. Entonces, yo llegué a Madrid, (...) a mí me estaba esperando en el aeropuerto un asistente de la Junta de Extremadura, que a mi papá lo llevaban a una residencia. (...) No podía venir a esta comunidad porque mi madre había muerto, entonces cada persona tiene que ir a su comunidad. (Teodosia, 58 años, peluquera, A Coruña, Galicia, septiembre de 2013)

La migración de Teodosia se planteó inicialmente en términos de familia nuclear. Viajarían ella, su marido y sus hijos. Sin embargo, su hermano, con 
quien trabajaba en Buenos Aires en un negocio familiar, le señaló que debía incluir también al padre de ambos.

Tanto Argentina como España son países en los que la historia del patriarcado es larga, y es frecuente que las hijas mujeres sean quienes se hacen cargo de los padres a medida que envejecen. De modo que Teodosia, la única hija mujer, optó por informarse respecto a las posibilidades que ofrecen las distintas comunidades autónomas para favorecer el retorno de sus compatriotas.

$\mathrm{Al}$ ser su padre de origen extremeño, ella optó por acudir a una asociación extremeña en Buenos Aires, donde recibió asesoramiento sobre los pasos a seguir para que lo admitieran en uno de los programas regionales para el retorno. De esta forma, al viajar a España, el padre fue recogido por el personal de una residencia para ancianos de la Junta de Extremadura y permaneció en dicha región durante cinco años, hasta que Teodosia consiguió su traslado a Galicia, donde tiempo después fallecería.

El relato de Teodosia es claro en relación con los procedimientos administrativos para el retorno de la diáspora y con las labores de cuidados familiares. No incluye ninguna crítica relativa a la distribución regional de las políticas para la diáspora, así como no lo hace respecto a la desigual asignación de responsabilidades familiares en la atención y el cuidado a otros miembros en función del género.

\section{Consideraciones finales}

En un momento histórico en que la Unión Europea está buscando armonizar las políticas migratorias de sus Estados miembros, algunos gobiernos subnacionales de España e Italia están desarrollando sus propias iniciativas con vistas a generar sus propias agendas transfronterizas (Tintori, 2009). En este contexto de gestión multinivel de las migraciones, este artículo ha examinado las políticas para la diáspora desarrolladas en dos regiones norteñas de estos países. Se han estudiado los antecedentes, las características, la evolución, las motivaciones y, de forma exploratoria, algunas consecuencias de estas iniciativas.

A través de dicho análisis, se ha advertido que los gobiernos de las regiones de Galicia y el Véneto han interpretado las migraciones decimonónicas de sus compatriotas como el resultado de carestías económicas regionales y, por ello, han desarrollado políticas para favorecer el desarrollo y el mantenimiento de vínculos e intercambios culturales, económicos y/o políticos con aquellos a quienes consideran como su diáspora.

Desde la perspectiva de estos gobiernos regionales, en varios países de América Latina - concretamente, Argentina, Chile, Brasil, Uruguay y Venezuelasiguen viviendo personas que forman parte de cada una de estas regiones $\mathrm{y}$, por tanto, merecen actuaciones específicas.

Estas actuaciones han sufrido un giro desde que comenzaran a implementarse entre las décadas de 1980 y 1990, pues han pasado de (a) buscar el reconocimiento y el mantenimiento de nexos con la diáspora, principalmente, a 
través de intercambios culturales, (b) a la promoción de leyes que delimitan quiénes son parte de la diáspora y quiénes no lo son en función de la distancia generacional que los separa de sus ancestros migrantes y, de ahí, (c) a establecer programas que buscan facilitar intercambios económicos a través del retorno y/o de vínculos empresariales.

Teniendo en cuenta que, en la literatura especializada, la difusión de este tipo de políticas a escala planetaria ha sido justificada, alternativamente, en términos económicos (Agunias y Newland, 2012) o étnico-culturales (Joppke, 2005), esta investigación ha permitido observar cómo en estas regiones ambas motivaciones han estado presentes desde que las medidas empezaran a implementarse, y cómo la motivación económica ha ido ganando terrero desde que comenzara el siglo XXI. Apreciación que coincide con las conclusiones de los estudios comparativos a escala nacional de (a) Ana Margheritis (2015), sobre el aumento de la instrumentalización política de la diáspora, y (b) Francesco Ragazzi (2014), sobre la tendencia creciente hacia la neoliberalización de estos mecanismos.

Tanto en Galicia como en el Véneto, se ha pasado del predominio de un discurso nacionalista de protección a la prevalencia de un discurso neoliberal, menos centrado en qué puede hacer la comunidad por la diáspora y más en qué puede hacer la diáspora por la comunidad. Es decir, si en la segunda mitad del siglo XX los contactos con la población en la diáspora se establecían, básicamente, a través del ámbito asociativo con la finalidad de conservar y fortalecer vínculos culturales, desde que se institucionalizara el nexo con leyes y programas a finales del siglo xx, los intercambios han adquirido un matiz cada vez más individualizado y economicista (prueba de ello son, respectivamente, las nuevas medidas de ayuda a emprendedores en Galicia y la red GlobalVen en el Véneto, ambos en vigor desde 2013). Dicho cambio se ha visto reflejado también en el derecho a voto en las elecciones regionales, garantizado solo a la diáspora gallega y no a la véneta. Pues, desde el cambio legislativo de 2011, para votar, la diáspora gallega debe solicitar o «rogar» el voto. Teniendo en cuenta investigaciones precedentes, como el estudio de John Skrentny, Stephanie Chan, Jon E. Fox y Denis Kim (2009), estos cambios pueden leerse como un alejamiento del estilo «europeo» y un acercamiento al estilo «asiático» en la gestión de los vínculos con la diáspora.

Frente a estos resultados del análisis antropológico de las políticas, el estudio de las narraciones de miembros de familias migrantes que pueden ser considerados diáspora española o italiana ofrece indicios de que este tipo de iniciativas ha tenido un éxito limitado entre aquella población que - supuestamente - regresa a la patria. Tanto quienes descienden de antepasados españoles o italianos como quienes lo hacen de antepasados gallegos o vénetos tienden a describir su migración más como una ida, o nueva migración, que como un retorno. De hecho, los migrantes tienden a vincular sus desplazamientos con sus situaciones (económicas, laborales y familiares) específicas. 
Esta constatación coincide con los resultados de las investigaciones llevadas a cabo por Takeyuki Tsuda (2009) y Tracey Reynolds (2008) respecto a otros migrantes que regresan a otras tierras de la que migraron sus ancestros, y concuerda tanto con las conclusiones del estudio de Laura Oso, Montserrat Golías y María Villares (2008) respecto a las migraciones procedentes de América Latina que tienen por destino Galicia, como con las de Melanie Fusaro (2009) respecto a ítalo-argentinos en la Región del Véneto.

Una aportación adicional de este trabajo ha sido la identificación de una diferencia generacional en las narraciones migrantes respecto a las políticas para la diáspora. Los padres y madres de las familias entrevistadas suelen afirmar que el hecho de contar con redes migratorias en la región de destino es crucial a la hora de tomar la decisión de desplazarse, dejando en un segundo plano el potencial recurso a mecanismos para la diáspora. Los hijos e hijas adultos, en cambio, tienden a distanciarse de estos mecanismos en un plano identificatorio; es decir, tienden a no verse a sí mismos como potenciales receptores de las políticas para la diáspora. Para ellos, el desplazamiento migratorio que han experimentado es el resultado de una decisión de sus padres y no se ven a sí mismos como potenciales beneficiarios de las políticas para la diáspora. Sus progenitores, en cambio, sí se identifican como posibles destinatarios que optan por utilizar otros recursos disponibles.

Un elemento relevante al analizar las narraciones de estos padres y madres ha sido identificar la actitud favorable que muestran hacia estas iniciativas. Con independencia de que pudieran beneficiarse o no de estas en función del origen regional de sus ancestros, la tendencia general de estos migrantes es la aceptación de estas medidas gubernamentales.

Frente a tal valoración, que va en la línea de la propuesta de Alan Gamlen (2008) de no cuestionar la «normalidad» de estas políticas, considero fundamental reexaminar críticamente este tipo de iniciativas desde la academia, sobre todo cuando estas se dirigen a los descendientes de emigrantes (la diáspora en sentido estricto). Pues facilitar la migración a grupos específicos de personas sobre la base de que se comparten vínculos nacionales/ regionales, étnicos, religiosos, culturales o lingüísticos, mientras se dificulta el acceso a otras personas consideradas diferentes, vulnera el Artículo 5 de la Convención de Naciones Unidas para la Eliminación de toda Forma de Discriminación Racial. Y eso es precisamente lo que han hecho las políticas para la diáspora desarrolladas desde estas regiones: diferenciar a la población en función de sus orígenes personales y familiares, favoreciendo los nexos e intercambios con aquellos a quienes se percibe como similares (Cook-Martin y Viladrich, 2009) en un momento histórico en el que las migraciones a Europa están siendo controladas y restringidas a personas con otros orígenes. Continuar indagando sobre las políticas para la diáspora desplegadas a diferentes escalas puede, por tanto, permitirnos mejorar nuestros conocimientos sobre iniciativas gubernamentales y repensar la base sobre la que se asientan las comunidades que habitamos. 


\section{Referencias bibliográficas}

ACTis, Walter y Esteban, Fernando (2007). «Argentinos hacia España ('sudacas' en tierras 'gallegas'): El estado de la cuestión». En: NovicK, Susana (ed.). Sur-Norte: estudios sobre la emigración reciente de argentinos. Buenos Aires: Catálogos.

Agunias, Dovelyn (2009). Closing the Distance, How Governments Strengthen Ties with their Diasporas. Washington DC: Migration Policy Institute.

Agunias, Dovelyn y NEWLAND, Kathleen (2012). Developing a Road Map for Engaging Diasporas in Development. A Handbook for Policymakers and Practitioners in Home and Host Countries. Washington DC: Migration Policy Institute.

AnCIEN, Delphine; Boyle, Mark y KITCHIN, Rob (2009). «Exploring Diaspora Strategies: An International Comparison». Workshop report. Maynooth: NUI Maynooth.

BrubaKer, Rogers (2005). "The 'Diaspora' Diaspora». Ethnic and Racial Studies, 28 (1), 1-19. <https://doi.org/10.1080/0141987042000289997>.

Cavas, Faustino y SÁnCHEZ, Carmen (2007). Derecho social de la región de Murcia. Murcia: Universidad de Murcia.

Charmaz, Kathy (2006). Constructing Grounded Theory: A Practical Guide through Qualitative Research. Londres: Sage.

CoOK-Martin, David (2013). The Scramble for Citizens: Dual Nationality and State Competition for Immigrants. Palo Alto: Stanford University Press. <https://doi.org/10.11126/stanford/9780804782982.001.0001>.

CoOK-Martin, David y Viladrich, Anahí (2009). "The Problem with Similarity: Ethnic-Affinity Migrants in Spain». Journal of Ethnic and Migration Studies, 35 (1), 151-170. <https://doi.org/10.1080/13691830802489309>.

DÉLANO, Alexandra y GAMLEN, Alan (2014). «Comparing and Theorizing State-Diaspora relations». Political Geography, 41, 43-53. <https://doi.org/10.1016/j.polgeo.2014.05.005>.

FARÍAS, Ruy (2008). "Distribución espacial, inserción socioprofesional y conducta matrimonial en un estudio de caso: Los gallegos en el partido de Avellaneda, 1890-1930». En: De Cristóforis, Nadia y FERnÁndeZ, Alejandro (ed.). Las migraciones españolas a la Argentina. Variaciones regionales, siglos XIX y XX. Buenos Aires: Editorial Biblos.

Feldman, Gregory (2012). The Migration Apparatus: Security, Labor, and Policymaking in the European Union. Palo Alto: Stanford University Press.

FUSARO, Melanie (2009). Les italo-argentins en Italie, 1998-2006: 'retour aux racines' ou nouveau départ? Paradoxes d'un mouvement migratoire contemporain. París: Editions L'Harmattan.

Gamlen, Alan (2008). «The Emigration State and the Modern Geopolitical Imagination». Political Geography, 27 (8), 840-856. <https://doi.org/10.1016/j.polgeo.2008.10.004>.

Gil ARAUjO, Sandra (2010). Las argucias de la integración: politicas migratorias, construcción nacional y cuestión social. Madrid: Editorial IEPALA.

Joppke, Christian (2005). Selecting by Origin: Ethnic Migration in the Liberal State. Nueva York: Harvard University Press.

Margheritis, Ana (2015). Migration Governance across Regions: State-Diaspora Relations in the Latin America-Southern Europe Corridor. Londres: Routledge. <https://doi.org/10.4324/9781315693897>. 
Nascimbene, Mario (1994). Italianos hacia América: Los flujos emigratorios regionales y provinciales peninsulares con destino al nuevo mundo (1876-1978). Buenos Aires: Centro de Estudios sobre Inmigración.

Oso, Laura; Golías, Montserrat y Villares, María (2008). «Inmigrantes extranjeros y retornados en Galicia: La construcción del puente transnacional». Politica y Sociedad, 45 (1), 103-117.

Ragazzi, Francesco (2014). "A Comparative Analysis of Diaspora Policies». Political Geography, 41 (1), 74-89. <https://doi.org/10.1016/j.polgeo.2013.12.004>.

Reynolds, Tracey (2008). «Ties that Bind: Families, Social Capital and Caribbean Second-Generation Return Migration». Sussex Migration Working Paper, 46, Brigthon: University of Sussex.

RHI-SAUSI, José Luis y GarCíA, Miguel Ángel (1992). Gli argentini in Italia: Una comunità di immigrati nel paese degli avi. Bologna: Synergon.

RovetTa CORTÉs, Ana Irene (2016). Políticas y pertenencias 'danzantes': migración familiar y políticas de retorno. Madrid: Editorial IEPALA.

SALDAÑA, Johnny (2009). The Coding Manual for Qualitative Researchers. Nueva York: Sage.

Shore, Cris y Wright, Susan (1997). Anthropology of Policy. Londres: Taylor \& Francis. $<$ https://doi.org/10.4324/9780203451038>.

SkrentnY, John; Chan, Stephanie; Fox, Jon E. y Kim, Denis (2009). «Defining Nations in Asia and Europe: A Comparative Analysis of Ethnic Return Migration Policy». En: TsudA, Takeyuki (ed.). Diasporic Homecomings. Stanford: Stanford University Press.

SKrBIS, Zlatko (1999). Long-Distance Nationalism: Diasporas, Homelands and Identities. Brookfield: Ashgate.

TINTORI, Guido (2009). Fardelli d'Italia. Conseguenze nazionali e transnazionali delle politiche di cittadinanza italiane. Roma: Carocci Editore.

TsuDA, Takeyuki (2009). Diasporic Homecomings. Stanford: Stanford University Press. 


\section{Anexo 1. Perfil de los migrantes considerados diáspora.}

Tabla 2. Cantidad de personas entrevistadas en función de la región, el género y la generación.

\begin{tabular}{lcccccccc}
\hline & & & \multicolumn{2}{c}{ Véneto } & & \multicolumn{2}{c}{ Galicia } \\
\cline { 8 - 9 } \cline { 7 - 8 } Personas entrevistadas & Total & & Mujeres & Hombres & & Mujeres & Hombres \\
\hline Hijos e hijas (menores de edad) & 12 & 4 & 3 & & 3 & 2 \\
Hijos e hijas (mayores de edad) & 13 & & 4 & 3 & & 1 & 7 \\
Padres y madres & 25 & & 7 & 6 & & 8 & 4 \\
Abuelas & 2 & 1 & - & & 1 & - \\
\hline
\end{tabular}

Fuente: elaboración propia, 2017 
Tabla 3. Información básica sobre los padres, madres, hijos e hijas adultos entrevistados: pseudónimo elegido, edad en el momento de la entrevista, década en que se produce la migración familiar, rol que ocupan en la familia, provincia (y región) de residencia, y ocupación en el momento de realizar la entrevista.

\begin{tabular}{|c|c|c|c|c|c|c|}
\hline Pseudónimo & Edad & Forma de contacto & $\begin{array}{l}\text { Década de } \\
\text { migración }\end{array}$ & $\begin{array}{c}\text { Rol } \\
\text { familiar }\end{array}$ & $\begin{array}{l}\text { Lugar de } \\
\text { residencia }\end{array}$ & Ocupación \\
\hline Leon Tolstoi & 20 & Asociación argentina & 2000 & Hijo & A Coruña (Galicia) & Estudiante universitario \\
\hline Capitán Nemo & 23 & Asociación argentina & 2000 & Hijo & Pontevedra (Galicia) & Estudiante universitario \\
\hline Andrea & 21 & Asociación argentina & 2000 & Hija & A Coruña (Galicia) & $\begin{array}{l}\text { Estudiante de formación } \\
\text { profesional }\end{array}$ \\
\hline Facundo & 24 & Técnica de bola de nieve & 2000 & Hijo & A Coruña (Galicia) & Estudiante universitario \\
\hline Jesús & 26 & Técnica de bola de nieve & 2000 & Hijo & A Coruña (Galicia) & Pasante en consultora \\
\hline Diego & 26 & Técnica de bola de nieve & 2000 & Hijo & A Coruña (Galicia) & Camarero \\
\hline Jose Mourigno & 30 & Técnica de bola de nieve & 2000 & Hijo & A Coruña (Galicia) & Desempleado \\
\hline Martín Fierro & 33 & Técnica de bola de nieve & 2000 & Hijo & A Coruña (Galicia) & Desempleado \\
\hline Adelma & 31 & Asociación argentina & 2000 & Madre & A Coruña (Galicia) & Trabajadora doméstica \\
\hline Amado & 40 & Asociación argentina & 2000 & Padre & A Coruña (Galicia) & Empleado de empresa local \\
\hline Alfredo & 38 & Técnica de bola de nieve & 2000 & Padre & Pontevedra (Galicia) & ) Gestor de hostelería \\
\hline Lola Mora & 38 & Técnica de bola de nieve & 2000 & Madre & Pontevedra (Galicia) & Trabajadora doméstica \\
\hline Monumento a la Bandera & 44 & Técnica de bola de nieve & 1990 & Madre & A Coruña (Galicia) & Cocinera \\
\hline Susanita & 46 & Asociación argentina & 2000 & Madre & A Coruña (Galicia) & Propietaria de negocio familiar \\
\hline Caña & 48 & Asociación argentina & 2000 & Padre & A Coruña (Galicia) & Propietario de negocio familiar \\
\hline María & 48 & Técnica de bola de nieve & 2000 & Madre & A Coruña (Galicia) & Asistente doméstico \\
\hline Micaela & 53 & Asociación argentina & 2000 & Madre & A Coruña (Galicia) & Asistente doméstico \\
\hline Isabel & 55 & Técnica de bola de nieve & 2000 & Madre & A Coruña (Galicia) & $\begin{array}{l}\text { Cuidadora y empleada en } \\
\text { sector de limpieza }\end{array}$ \\
\hline Teodosia & 58 & Técnica de bola de nieve & 2000 & Madre & A Coruña (Galicia) & Propietaria de negocio familiar \\
\hline Peluca & 61 & Técnica de bola de nieve & 2000 & Padre & A Coruña (Galicia) & Propietario de negocio familiar \\
\hline Juanito & 20 & Asociación argentina & 1980 & Hijo & Padua (Véneto) & Estudiante universitario \\
\hline Julia & 26 & Asociación argentina & 1980 & Hija & Padua (Véneto) & Estudiante universitaria \\
\hline Luisito & 26 & Técnica de bola de nieve & 1990 & Hijo & Treviso (Véneto) & Estudiante universitario \\
\hline Serena & 40 & Técnica de bola de nieve & 1980 & Hija & Vicenza (Véneto) & Ingeniera en empresa local \\
\hline Norah & 46 & Técnica de bola de nieve & 1980 & Hija & Vicenza (Véneto) & Contadora en pequeña empresa \\
\hline Rosa & 31 & Técnica de bola de nieve & 2000 & Madre & Vicenza (Véneto) & Trabajadora doméstica \\
\hline Pedro & 37 & Técnica de bola de nieve & 2000 & Padre & Vicenza (Véneto) & Cocinero \\
\hline Rita & 40 & Técnica de bola de nieve & 2000 & Madre & Vicenza (Véneto) & Cuidadora \\
\hline Pepe & 45 & Técnica de bola de nieve & 2000 & Padre & Vicenza (Véneto) & Trabajador en fábrica \\
\hline Silvana & 43 & Técnica de bola de nieve & 1990 & Madre & Padua (Véneto) & Trabajadora doméstica \\
\hline Matilde & 43 & Asociación argentina & 2000 & Madre & Padua (Véneto) & Profesora de clases particulares \\
\hline Paturuzú & 45 & Asociación argentina & 2000 & Padre & Vicenza (Véneto) & Técnico electricista \\
\hline Lucho & 52 & Técnica de bola de nieve & 1990 & Padre & Treviso (Véneto) & Trabajador en fábrica \\
\hline Mafalda & 53 & Asociación argentina & 1980 & Madre & Padua (Véneto) & Trabajadora de empresa \\
\hline Regina & 69 & Técnica de bola de nieve & 1990 & Madre & Vicenza (Véneto) & Trabajadora doméstica \\
\hline Nicolás I & 72 & Técnica de bola de nieve & 1990 & Padre & Vicenza (Véneto) & Jubilado de trabajo en fábrica \\
\hline Samantha & 69 & Técnica de bola de nieve & 1980 & Madre & Vicenza (Véneto) & Trabajadora doméstica \\
\hline Tony Bennett & 73 & Técnica de bola de nieve & 1980 & Padre & Vicenza (Véneto) & Carpintero jubilado \\
\hline
\end{tabular}

Fuente: elaboración propia, 2017 